\title{
Drug suicide risks prompt call for FDA action
}

\section{Erika Check, Washington}

A scientific advisory panel has joined a chorus of patient groups and consumer advocates this week in calling for the US Food and Drug Administration (FDA) to curb the use of certain antidepressant medications in young people.

"We would like the FDA to go ahead and issue a stronger warning to clinicians regarding the possible risks of these medicines," says psychiatrist Matthew Rudorfer of the National Institute of Mental Health in Bethesda, Maryland. Rudorfer chairs a committee that met on 2 February to advise the FDA on certain antidepressant medications in patients aged 17 and under. But the committee said that the drugs should not be banned.

The meeting followed a decision

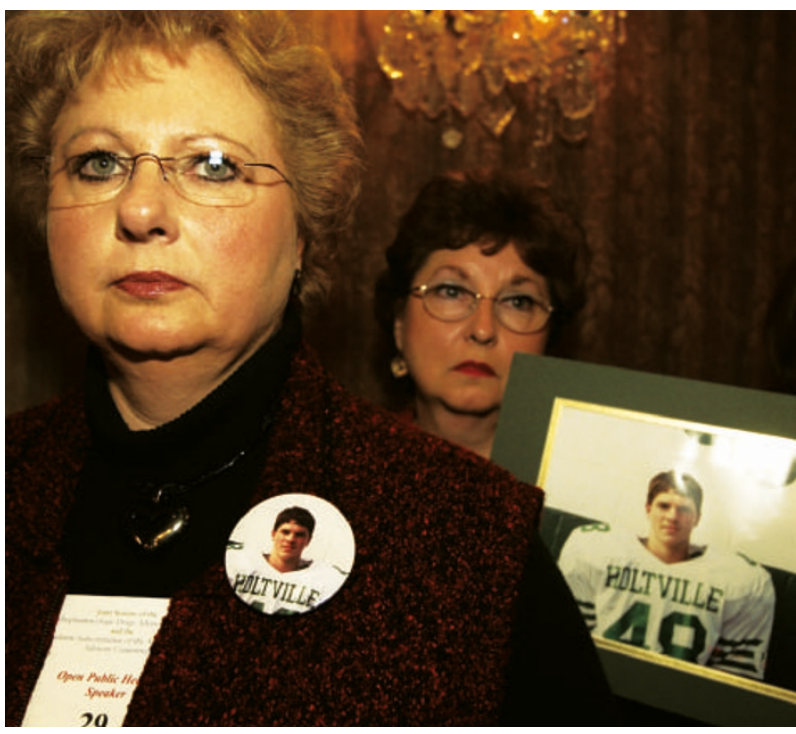

Terri Williams (left) waits to give testimony at a public hearing: her 14-year-old son Jacob committed suicide while on antidepressants.

that there's "enough of a signal here" to suggest that something is amiss.

But the FDA says that the data are inconclusive, and wants more information before following the British ban. It has therefore asked a group of researchers at Columbia University, New York, to help it to reanalyse the data from the drugcompany studies.

Scientists on the committee predicted that the outside analysis would not answer the basic question of whether the drugs cause children to try to kill themselves. They pointed out that corporate studies are not designed to measure how the medications affect the risk of suicide. "I don't have a lot of hope for you being able to get good information out of the planned reanalysis," says Judith O'Fallon, a panel member and biostatistician at the by British regulators on 10 December last year to ban doctors from treating children with five antidepressant drugs classified as 'selective serotonin reuptake inhibitors', or SSRIs. The British decision was based on an assessment of drug-company data suggesting that the drugs were not proven to be effective in young people, but marginally increased the risk that they would commit suicide.

The UK Medicines and Healthcare Products Regulatory Agency ruled that only one drug of this type - fluoxetine, better known as Prozac — was beneficial enough to justify the risk of side effects, and should be pre-

scribed to children. In the United States, Prozac is the only SSRI that has been approved by the FDA for use in children, but others are nonetheless frequently prescribed by physicians.

The committee meeting heard emotional testimony from parents whose children had committed suicide while on SSRIs. Some parents raised concerns about the accuracy of published literature on the drugs.

Thomas Laughren, an FDA official responsible for psychiatric drugs, told the committee that the FDA's approach to the drugs was based on identical data to those considered by British regulators. He says
Mayo Clinic in Rochester, Minnesota.

The panel said that the FDA should still go ahead with its reanalysis of the data but should also do more to caution physicians about the risks posed by the drugs. FDA officials said they would consider this advice, but that the agency had already sent out a warning to doctors last October and was not planning major regulatory action before completing its reanalysis this summer. The officials added that smaller steps could be taken in the meantime, such as changing the labelling of the drugs, and including more information in leaflets that accompany them.

\section{Europe urged to move on transgenic crop imports}

Quirin Schiermeier, Munich

The president of the European Commission last week called for an end to Europe's effective moratorium on the growth and importation of genetically modified crops.

Supporters of agricultural biotechnology are hoping that a letter from Romano Prodi to the commissioners of the European Union's (EU's) 15 member states will mark the beginning of the end of the moratorium. The letter, sent on 28 January, urges member states to restart the approval process for the crops to avoid a trade war with the United States. But the jury is still out on whether Prodi's message will make much difference.

The EU hasn't given the go-ahead for the importation or cultivation of any genetically modified crop since October 1998, and last August a World Trade Organization panel was set up to consider a complaint from the United States, Canada and Argentina that the go-slow violates its trading rules.

Last year, the EU passed laws stipulating the labelling and traceability of the crops. The laws come into effect in April. "Now that the necessary legislative decisions have been taken," Prodi wrote in his letter, "it is important to demonstrate to the European public and to our trade partners that the EU system of authorisation is working as designed."

Currently, 22 applications are awaiting approval across the EU. The first in line and an acid test of the new policy - is a request to import an insect-resistant sweetcorn variety called Bt11, developed by the Swiss firm Syngenta and grown in the United States.

In December, a regulatory committee failed to reach the qualified majority required to permit importation of the corn. The matter will now go to a council of ministers from member states, which has three months to make a decision. But if the council fails to achieve the necessary majority either in favour or against - as many observers predict - the European Commission will decide. If that happens, imports are likely to start as early as April.

One crop that is unlikely to be approved is herbicide-tolerant oilseed rape, marketed by Bayer CropScience in Monheim am Rhein, Germany, and submitted for approval to the Belgian government. Ministers ruled against the application on 2 February after studying the results of a British report that found that the herbicide-spraying regime associated with oilseed rape could harm the environment. 